\title{
Erratum to: Concentration of antibodies against Porphyromonas gingivalisis increased before the onset of symptoms of rheumatoid arthritis
}

Linda Johansson ${ }^{1 \dagger}$, Natalia Sherina ${ }^{2 \dagger}$, Nastya Kharlamova ${ }^{2}$, Barbara Potempa ${ }^{3}$, Barbro Larsson ${ }^{2}$, Lena Israelsson², Jan Potempa ${ }^{3,4}$, Solbritt Rantapää-Dahlqvist ${ }^{{ }^{* \dagger}}$ and Karin Lundberg ${ }^{2 \dagger}$

\section{Erratum}

Unfortunately, after publication of this article [1], it was noticed that the $\mathrm{x}$-axis markers for Fig. $2 \mathrm{a}$ and $\mathrm{b}$ were incorrect. The corrected figure can be seen below.

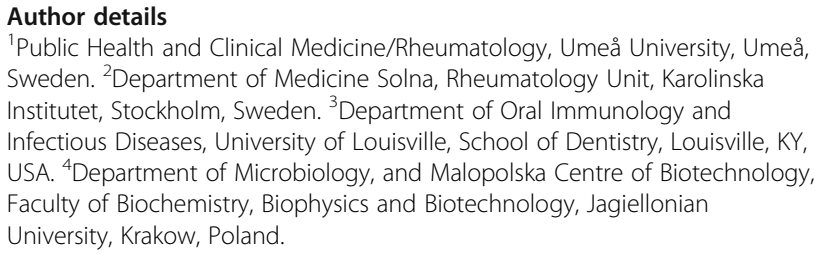

Received: 24 October 2016 Accepted: 25 October 2016

Published online: 04 November 2016

\section{Reference}

1. Johansson L, Sherina N, Kharlamova N, Potempa B, Larsson B, Israelsson L, Potempa J, Rantapää-Dahlqvist S, Lundberg K. Concentration of antibodies against Porphyromonas gingivalis is increased before the onset of symptoms of rheumatoid arthritis. Arthritis Res Ther. 2016;18:201. doi:10.1186/s13075-016-1100-4

\footnotetext{
* Correspondence: solbritt.rantapaa.dahlqvist@umu.se

${ }^{\dagger}$ Equal contributors

${ }^{1}$ Public Health and Clinical Medicine/Rheumatology, Umeå University, Umeå, Sweden
} 


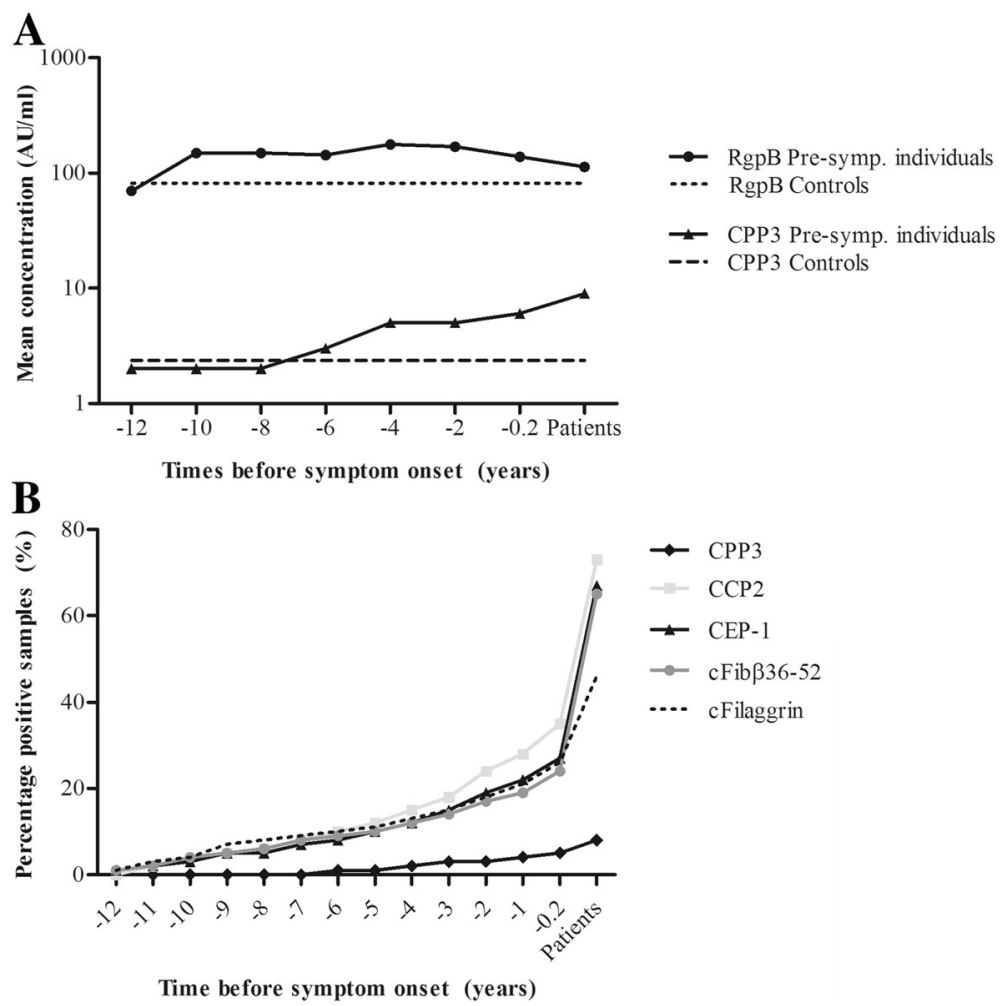

Fig. 2 Antibody responses during the pre-dating time until the time point for onset of symptoms of RA, from pre-symptomatic individuals who donated multiple blood samples pre-dating the onset of symptoms of RA $(n=422)$ and from patients with RA $(n=192)$. Logarithmic mean concentrations during 2-year periods of anti-RgpB and anti-CPP3 antibodies in pre-symptomatic individuals, patients with RA and controls $(n=198)$ (a). Accumulated percentages of antibody positivity for anti-CPP3, anti-CCP2, anti-cfibrinogenß36-52 (cFibß36-52), anti-CEP-1 (a-enolase) and anti-cfilaggrin (cFilaggrin) antibodies in pre-symptomatic individuals and in patients with RA (b). 0 time point for onset of RA symptoms 